\title{
The Effects of 1-Methylcyclopropene in the Regulation of Antioxidative System and Softening of Mango Fruit during Storage
}

\author{
Li Li (iD, ${ }^{1,2}$ Changbao Li, ${ }^{1,2}$ Jian Sun $\mathbb{D}^{1},{ }^{1,2}$ Jinfeng Sheng, ${ }^{1,2}$ Zhugui Zhou, ${ }^{1}$ Ming Xin, ${ }^{1}$ Ping Yi, ${ }^{1}$ \\ Xuemei He, ${ }^{1}$ Fengjin Zheng, ${ }^{1}$ Yayuan Tang, ${ }^{1}$ Jiemin Li, ${ }^{1}$ and Jie Tang ${ }^{1}$ \\ ${ }^{1}$ Agro-food Science and Technology Research Institute, Guangxi Academy of Agricultural Sciences, 174 East Daxue Road, \\ 530007 Nanning, China \\ ${ }^{2}$ Guangxi Key Laboratory of Fruits and Vegetables Storage-processing Technology, 174 East Daxue Road, 530007 Nanning, China
}

Correspondence should be addressed to Jian Sun; jiansun@gxaas.net

Received 23 July 2019; Revised 21 January 2020; Accepted 6 March 2020; Published 6 April 2020

Guest Editor: Juan Luis Valenzuela

Copyright (c) $2020 \mathrm{Li} \mathrm{Li} \mathrm{et} \mathrm{al.} \mathrm{This} \mathrm{is} \mathrm{an} \mathrm{open} \mathrm{access} \mathrm{article} \mathrm{distributed} \mathrm{under} \mathrm{the} \mathrm{Creative} \mathrm{Commons} \mathrm{Attribution} \mathrm{License,} \mathrm{which}$ permits unrestricted use, distribution, and reproduction in any medium, provided the original work is properly cited.

\begin{abstract}
The function of 1-methylcyclopropene (1-MCP) in the regulation of quality and antioxidative system of mango fruit was investigated during storage at ambient temperature. Changes in fruit quality, colour, ethylene production, respiration rate, fruit softening enzyme activities, and antioxidative enzyme activities were studied in this study. The results demonstrated that 1-MCP was beneficial for maintaining quality. 1-MCP treatment retarded the decline of firmness, weight, total soluble solid, and titratable acidity, which served as significant parameters for assessing fruit quality in the process of storage. Compared with the fruit of the control group, the treatment with 1-MCP dramatically delayed the colour change of both the pulp and peel and suppressed climacteric peaks of ethylene generation and respiration speed. The significant inducement of peroxidase, catalase, and superoxide dismutase activities were followed by 1-MCP treatment. The fruit treated with 1-MCP displayed significantly inhibited activation of enzymes on the cell wall, i.e., pectin esterase (PE), endo-1,4- $\beta$-d-glucanase (EGase), exopolygalacturonase (exo-PG), and endopolygalacturonase (endo-PG), during storage. The results suggested that 1-MCP imposed underlying impact on the maintenance of the softening and extension of postharvest life of mango fruit.
\end{abstract}

\section{Introduction}

As one of the most significant fruits, mango (Mangifera indica Linn.) is recognized as the "King's fruit" in tropical and subtropical regions [1]. Mango contains a great deal of substantial quantity of distinct appreciable carotene, vitamin $\mathrm{C}$, dietary fiber, soluble sugars, and diversified minerals, which are employed as favorable nutrient sources and readily existing as well as assumable with ease in the bodies of human beings, thereby making it capable of avoiding abundant deficiency diseases [2,3]. Mango is a kind of climacteric fruit whose ripening is triggered as well as proceeded by a surge in ethylene generation along with a significant increase in respiration speed. Generally, the harvest of the fruit occurs on the green-ripening stage, followed by the transportation and storage when temperature is maintained at a low level $\left(10^{\circ} \mathrm{C}-15^{\circ} \mathrm{C}\right)$ for the extension of the expiration date [4]. However, the continuous occurrence of severe postharvest diseases causes abundant postharvest decay [5]. Every year, postharvest decay is responsible for the waste of a great deal of fresh mango fruits [6]. The main elements responsible for the storage of mango are softening and microbial corruption [7].

Softening, which is partially controlled by endogenous ethylene biosynthesis, is one of the main factors that reduces fruit quality and leads to economically important losses [8]. As one of some regulators responsible for plant progress, ethylene is capable of affecting growth and progressing processes such as maturity and aging [9]. In the process of postharvest storage, ethylene is capable of imposing undesirable impacts such as aging, rapid quality loss, decrease in nutrient composition, increase in fruit pathogen susceptibleness, and physiological disturbance among fruits [10]. Consequently, it is essential to inhibit ethylene biosynthesis 
or its action to slow down the processes of maturity and step up the disease resistance of the fruit. 1-Methylcyclopropene (1-MCP), as an ethylene action inhibitor, has been proven to be effective in retarding senescence process by binding irreversibly to the ethylene-binding receptor, thereby inhibiting the ethylene signal transduction pathway, such as in mango [11, 12], pear [13], sweet cherry [14], apple [15], and jujube [16] and is widely used to control ripening and senescence and extend postharvest storage life in climacteric fruits.

The postharvest employment of 1-MCP which can retard maturity and keep up quality in mango has been indicated. For instance, Razzaq et al. reported that 1-MCP inhibited fruit softening enzyme activities, consequently delaying the maturity and variations associated with it in "Kensington Pride" mango [17]. 1-MCP could also play a positive part in the regulation of the activated oxygen metabolism balance [18]. However, reports on the mechanisms of 1-MCP which delays softening and antioxidative system are rare. The main objectives of this research were to study the impacts of 1MCP in regulating fruit softening, its characteristics in physiology, and antioxidant enzyme activity variations in the stored mango fruit, so as to investigate the mechanism of 1MCP in delaying ripening.

\section{Materials and Methods}

2.1. Plant Materials and Treatments. Mango fruits (Mangifera indica L. cv. Tainong) were reaped from an orchard in Baise city, Guangxi province of China. Fruits were then stored, which were about $12 \mathrm{~cm}$ in length and $8 \mathrm{~cm}$ in width without any physical injury or infection.

The initial results of our experiments demonstrated that $1 \mu \mathrm{L} / \mathrm{L}$ of $1-\mathrm{MCP}$ (Ethyl Bloc, Rohm and Haas China, Inc.) played a better role in maintaining mango fruit quality. Mango fruit were separated into two halves at random, enclosed in a plastic container, and treated with 1-MCP, which was prepared from a commercial powder dissolved in sterile distilled water, and the final concentration was $1 \mu \mathrm{L} / \mathrm{L}$ equal volume of sterile water which was used as the control. 1-MCP was dissolved in sterile distilled water at a final concentration of $1 \mu \mathrm{L} / \mathrm{L}$. The fruit were treated with $1-\mathrm{MCP}$ for $24 \mathrm{~h}$ at $25^{\circ} \mathrm{C}$ and subsequently stored at $25^{\circ} \mathrm{C}$ and were then collected every two days, frozen in liquid nitrogen, and stored at $-80^{\circ} \mathrm{C}$ until analysis. Three replicates per analysis were used for all measurements.

\subsection{Assessment of Fruit Quality}

2.2.1. Firmness and Weight Loss. Firmness of the fruit flesh was measured using a handheld penetrometer (FT-327; UCFruit Firmness Tester, Milano, Italy) equipped with a probe $8 \mathrm{~mm}$ in diameter. A small slice of fruit skin was removed, and the firmness was recorded from three different pieces of fruit with three different points per fruit and then means were expressed as Newtons $(\mathrm{N})$. The weight loss of mango fruit was evaluated according to the method by $\mathrm{Li}$ et al. [19]. The initial weight of each tray and the weight at each sampling interval were measured using an F1004A analytical balance (Shanghai ShangTian Precision Instrument, Shanghai, China). The results were expressed as percentages of the fresh weight (FW).

\subsubsection{Contents of Total Soluble Solid and Titratable Acidity.} Total soluble solid (TSS) levels of mango fruit were determined according to the AOAC method [20], using a hand refractometer (Atago, Tokyo, Japan). Titratable acidity (TA) contents were determined using an automatic titrator (Titroline easy, Schott, Mainz, Germany) by titration of the sample to $\mathrm{pH} 8.2$ with $0.1 \mathrm{~N} \mathrm{NaOH}$. Results were expressed as percentage of citric acid (grams of citric acid per $100 \mathrm{~g}$ fresh weight).

2.2.3. Colour Measurements. Colour of both peel and pulp was measured for both the red and green sides of each fruit immediately after opening each package on each sampling day during storage. A CR-400 Chroma Meter (Konica Minolta Sensing Americas Inc., Ramsey, NJ, USA) with an 8$\mathrm{mm}$ viewing port and an illuminant D65 was used for measuring CIE $\mathrm{a}^{*}$ (redness) and $\mathrm{b}^{*}$ (yellowness) values [21].

2.2.4. Rates of Ethylene Production and Respiration. Postharvest fruit from the 1-MCP-treated and control groups were placed in pure $\mathrm{N}_{2}$ and subsequently stored at $20^{\circ} \mathrm{C}$ with $90 \%$ relative humidity. Three fruits were placed in a $4.2 \mathrm{~L}$ airproof glass jar for $2 \mathrm{~h}$ at $25^{\circ} \mathrm{C}$ to determine the rates of ethylene production at different storage stages. A headspace gas sample $(1 \mathrm{~mL})$ was collected from each jar and analyzed using a GC-2014C gas chromatograph (Shimadzu, Kyoto, Japan). Subsequently, a thermal conductivity detector (Shimadzu TCD-2014) with the Porapak N column was used to detect the concentration of carbon dioxide in the samples. The levels of ethylene were determined using a flame ionization detector and an OV-17 capillary column (Zhonghuida Co., Dalian, China). The rates of ethylene production and respiration are presented on $\mathrm{FW}$ basis as mentioned above.

\subsection{Impacts on Oxidative Stress}

2.3.1. MDA Content. The measurement of malondialdehyde (MDA) level was achieved on the basis of the reported approach by Sun et al. with a mild alteration [22]. The homogenization of mango pulp tissues $(3 \mathrm{~g})$ were achieved with $10 \%$ trichloroacetic acid of $15 \mathrm{~mL}$, followed by centrifugation at $15000 \times \mathrm{g}$ for $20 \mathrm{~min}$. The mixture of 1 milliliter of supernatant and $0.5 \%$ 2-thiobarbituric acid of $3 \mathrm{~mL}$ was made, followed by heating for $20 \mathrm{~min}$ at $95^{\circ} \mathrm{C}$ and cooling right away in a basin filled with cold water. The absorbance was spectrophotometrically measured at $532 \mathrm{~nm}$ (UV 1600 PC, Shimadzu, Tokyo, Japan) after being centrifuged at $3000 \times g$ for $10 \mathrm{~min}$, along with the subtraction of nonspecific absorbance values $600 \mathrm{~nm}$. The estimation of the quantity of MDA was done as follows: $(\mu \mathrm{M} / \mathrm{gFW})=\left[6.45\left(\mathrm{OD}_{532}-\mathrm{OD}_{600}\right)-0.56\right.$ $\left.\mathrm{OD}_{450}\right] \times 5 \mathrm{~mL} / 0.25 \mathrm{~g}$. 
2.3.2. Activities of Antioxidative Enzymes. Catalase (CAT) and peroxidase (POD) were extracted and assayed on the basis of the improved ways by Vicente et al. and Liu et al. $[23,24]$. $0.1 \mathrm{M}$ sodium phosphate buffer ( $\mathrm{pH} 7.0$ ) of $2.5 \mathrm{~mL}$ was used to draw mango pulp tissues $(1 \mathrm{~g})$ for $10 \mathrm{~min}$ at $4^{\circ} \mathrm{C}$, with extracting liquid being centrifuged for fifteen min at $12000 \times \mathrm{g}$. The enzymatic activities were determined by collecting the supernatant. The assay mixture consisting of $15 \mathrm{~m} \cdot \mathrm{M} \cdot \mathrm{H}_{2} \mathrm{O}_{2}$ of $2.8 \mathrm{~mL}$ was made by $0.05 \mathrm{M}$ sodium phosphate buffer ( $\mathrm{pH} 7.8$ ) and an enzyme solution of $0.2 \mathrm{~mL}$, which was used for the determination of CAT activity. The addition in absorbance at $240 \mathrm{~nm}$ for $3 \mathrm{~min}$ at $25^{\circ} \mathrm{C}$ was recorded. A unit of CAT activity was specified as the enzyme quantity causing a variation of 0.001 in absorbance every minute. POD activity was determined by the assay compound containing $0.1 \mathrm{M}$ sodium phosphate buffer $(\mathrm{pH} 7.0)$ of $2.5 \mathrm{~mL}, 0.46 \%(\mathrm{v} / \mathrm{v}) \mathrm{H}_{2} \mathrm{O}_{2}$ of $0.2 \mathrm{~mL}, 4 \%(\mathrm{v} / \mathrm{v})$ guaiacol of $0.2 \mathrm{~mL}$, and enzyme solution of $0.1 \mathrm{~mL}$. The addition in absorbance at $470 \mathrm{~nm}$ for $3 \mathrm{~min}$ at $25^{\circ} \mathrm{C}$ was recorded. One unit of POD activity was specified as the enzyme quantity causing a variation of 0.01 in absorbance every minute.

The extraction and assay were achieved through superoxide dismutase (SOD) based on the improved way given by Wang and Tian [12]. $0.1 \%(\mathrm{w} / \mathrm{v})$ polyvinyl pyrrolidone was contained in $5 \mathrm{~mL}$ of $0.05 \mathrm{M}$ sodium phosphate buffer ( $\mathrm{pH} 7.8$ ), with which, mango pulp tissues ( $1 \mathrm{~g}$ ) were extracted for $10 \mathrm{~min}$ at $4^{\circ} \mathrm{C}$. The extracting solution was centrifuged for $20 \mathrm{~min}$ at $12000 \times \mathrm{g}$. SOD activity was determined by collecting the supernatant. The SOD activity determination was achieved through the measurement of its capacity to suppress the photochemical reduction of nitro blue tetrazolium (NBT). $0.05 \mathrm{~mL}$ of enzyme liquid in all were increased into three $\mathrm{mL}$ of the assay reagent which was composed of $13 \mathrm{mM}$ methionine, $100 \mu \mathrm{M}$ EDTA, $63 \mu \mathrm{M} \mathrm{NBT}$, and $1.3 \mu \mathrm{M}$ riboflavin in $0.05 \mathrm{M}$ sodium phosphate buffer ( $\mathrm{pH}$ 7.8). The reaction solutions were incubated for $10 \mathrm{~min}$ in the illumination of 4000 lux. The measurement of absorbance of sample was achieved at $560 \mathrm{~nm}$, with $0.05 \mathrm{M}$ of sodium phosphate buffer ( $\mathrm{pH} 7.8$ ) as the control. 1 unit of enzymatic activity was specified as the enzyme quantity causing $50 \%$ suppression of NBT reduction.

2.4. Activities of Fruit Softening Enzymes. For enzyme extraction, $150 \mathrm{~g}$ of mango pulp tissues were ground in a homogenizer with $100 \mathrm{~mL}$ of cold aqueous solution containing polyethylene glycol $12 \%$ and $0.2 \%$ sodium bisulfite for $2 \mathrm{~min}$. After centrifugation at $10,000 \times \mathrm{g}$ for $10 \mathrm{~min}$ at $5^{\circ} \mathrm{C}$, the pellet was collected and separated into four parts for extraction of each enzyme activity.

2.4.1. Exo-PG and Endo-PG Activity. For exo-PG and endo$\mathrm{PG}$, the pellet was incubated in a shaker at $4^{\circ} \mathrm{C}$ for $1 \mathrm{~h}$ in cold $50 \mathrm{mM} \mathrm{Na}$ acetate buffer pH 5, 0.5 M NaCl. After centrifugation was done as mentioned above, the supernatant was diluted once with $50 \mathrm{mM} \mathrm{Na}$ acetate buffer, $\mathrm{pH}$ 5, and was used as the crude extract. For determination of the exo-PG activity, the enzyme extract $(1 \mathrm{~mL})$ was mixed with an equal volume of $0.5 \%$ polygalacturonic acid in $50 \mathrm{mM} \mathrm{Na}$ acetate buffer, $\mathrm{pH} 4.4$, and incubated at $30^{\circ} \mathrm{C}$ for $18 \mathrm{~h}$. For the determination of galacturonic acid released, $2 \mathrm{~mL}$ borate buffer ( $0.1 \mathrm{M}, \mathrm{pH} 9.0)$ and $0.3 \mathrm{~mL} 1 \%$ cyanoacetamide were added to the reaction mixture, boiled for $10 \mathrm{~min}$, and then cooled and read at $274 \mathrm{~nm}$. Galacturonic acid was used as a standard, and controls of the boiled extract were run. One activity unit was $1 \mathrm{mg}$ of galacturonic acid released per mg of protein per $h$. The endo-PG activity was measured in a Cannon-Fenske viscometer (Model N.100, USA) by mixing $3 \mathrm{~mL}$ of the enzyme extract with $4.5 \mathrm{~mL}$ of $2 \%$ polygalacturonic acid (Sigma Chemical Company, G-2125, USA) in $50 \mathrm{mM} \mathrm{Na}$ acetate, $\mathrm{pH}$ 4.4. Initial viscosity was measured and also measured after a further incubation for $18 \mathrm{~h}$ at $30^{\circ} \mathrm{C}$ [25]. One activity unit was defined as the change in viscosity per $g$ of per mg protein per $h$.

2.4.2. PE Activity. For PE extraction, the pellet was resuspended into $15 \mathrm{~mL} 7.5 \% \mathrm{NaCl}$ and $0.75 \%$ EDTA (pH 6.5) and incubated at $4^{\circ} \mathrm{C}$ for $10 \mathrm{~min}$. Following centrifugation as above, the supernatant was collected. Crude extract $(5 \mathrm{~mL})$ was mixed with $20 \mathrm{~mL} 1 \%$ citrus pectin and titrated with $0.01 \mathrm{~N} \mathrm{NaOH}$ to maintain $\mathrm{pH} 7.4$, while incubating at $30^{\circ} \mathrm{C}$. The reaction was found to be linear for $2 \mathrm{~h}$, but normally, the reaction was measured for $30 \mathrm{~min}$. One unit activity was calculated as $1 \mathrm{mM} \mathrm{NaOH}$ consumed per mg protein per h.

2.4.3. EGase Activity. For EGase activity, the pellet was stirred in $15 \mathrm{~mL} 0.1 \mathrm{M}$ citrate phosphate buffer, $\mathrm{pH} 6.0$, and $1 \mathrm{M} \mathrm{NaCl}$ at $4^{\circ} \mathrm{C}$ for $1 \mathrm{~h}$ and then centrifuged as above. Using the supernatant as the crude extract, enzyme activity was measured by the change in viscosity as for endo-PG. The reaction mixture contained $6 \mathrm{~mL} 0.2 \%$ methyl cellulose (CMC) in citrate phosphate buffer and $3 \mathrm{~mL}$ of the supernatant.

2.5. Analysis on Statistics. Every experiment was carried out three times $(n=3)$, along with comparison of the average values of every treatment through an ANOVA test (employing SPSS 13.0 statistical software, SPSS Inc., Chicago, USA). The LSD test was employed to determine whether the means of parameters are significantly different $(P<0.05)$, with consequences demonstrating average \pm standard error (SE) of determinations three times repeatedly.

\section{Results}

3.1. Effects of 1-MCP on Fruit Quality. From Figure 1(a), a decreasing trend in the firmness of mango was observed during ambient storage in both 1-MCP-treated and control groups over the first six days during the storage; however, there was no significant change after the 6-d storage. The loss of fruit firmness in fruit was significantly delayed $(P<0.05)$ in the 1-MCP-treated group compared with that in the control group. Weight loss is a natural process observed in the postharvest stage. As shown in Figure 1(b), all the samples exhibited increased weight loss during storage. Along with an increase in storage time, weight loss of 1MCP-treated mango was significantly lower than the control 


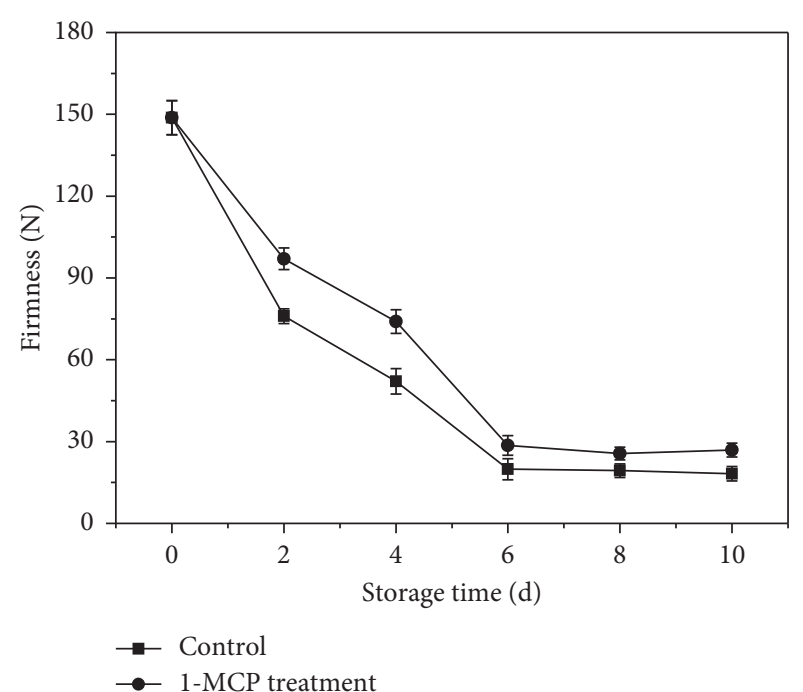

(a)

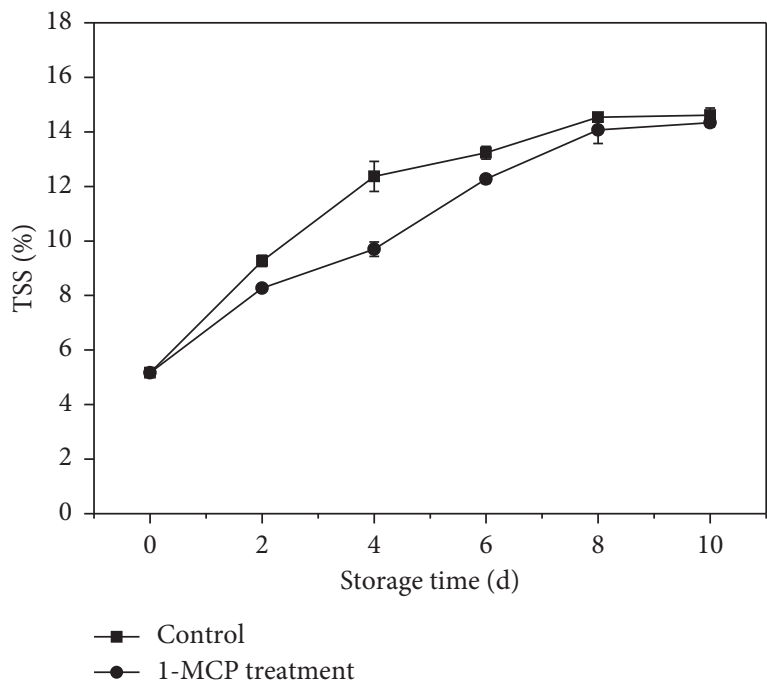

(c)

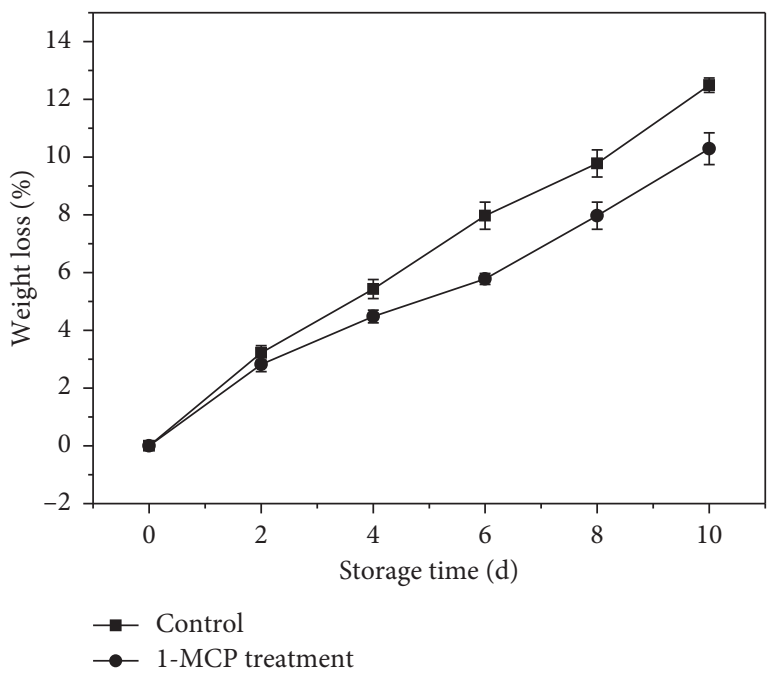

(b)

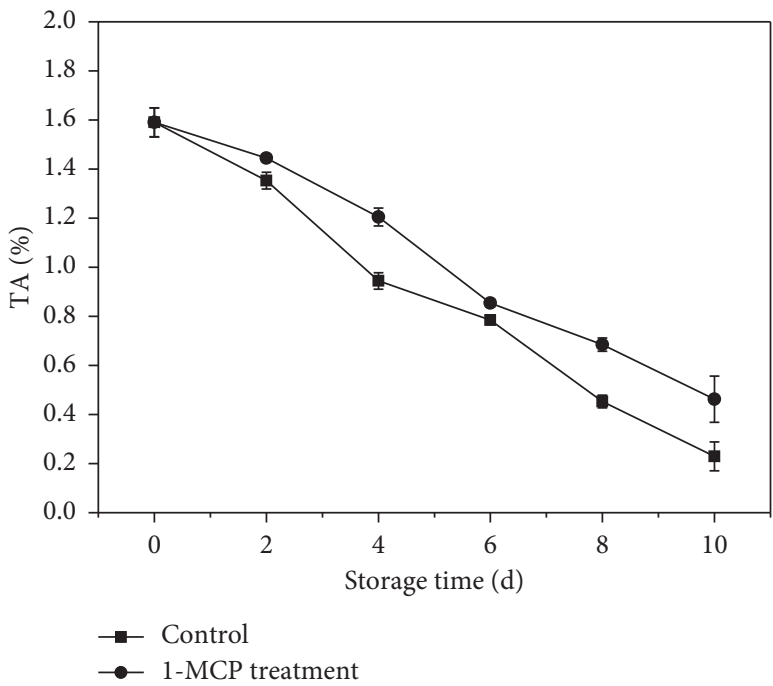

(d)

Figure 1: Effects of 1-MCP treatment on firmness (a), weight loss (b), TSS (c), and TA (d) of mango fruit during storage at $25^{\circ} \mathrm{C}$. The data are the means of triplicates \pm standard deviations.

group after 4 days $(P<0.05)$, suggesting that the1-MCP treatment was much more effective in reducing the weight loss of mango fruit. From Figure 1(c), the TSS content in the pulp tissues of both groups was shown to increase as the storage duration extended. However, the TSS content in the 1-MCP-treated group was significantly lower than that recorded in the control group, especially on day 4 of storage $(P<0.05)$. TA decreased with the extend in storage time (Figure 1(d)). TA in fruit treated with $1-\mathrm{MCP}$ was significantly lower $(P<0.05)$ than that in control on days 4,8 , and 10 of storage (all $P<0.05$ ).

3.2. Effects of 1-MCP on Fruit Colour. Changes in colour of mango peel and pulp during storage are presented in Figure 2. From Figure 2(a), compared with the control group, the use of 1-MCP delayed the colour change and occurrence of deterioration during storage, and fruit treated with 1-MCP maintained higher overall quality throughout the storage period of 10 days. The obvious increase of $a^{*}$ and $b^{*}$ values indicated the senescence of mango fruit. As shown in Figure 2(b), the $a^{*}$ value of mango peel increased with storage time, and the $\mathrm{a}^{*}$ value of the 1 -MCP-treated group was significantly $(P<0.05)$ higher than the control group after 6 days. From Figure 2(c), the $b^{*}$ value increased steadily in both treatments during the 10-day storage, and the control had the faster increase rate than the mango treated with 1MCP. The changes in $\mathrm{a}^{*}$ and $\mathrm{b}^{*}$ values of mango pulp were also analyzed. From Figures 2(d) and 2(e), the $\mathrm{a}^{*}$ and $\mathrm{b}^{*}$ values of the 1-MCP-treated group were lower than those of the control group throughout the storage period of 10 


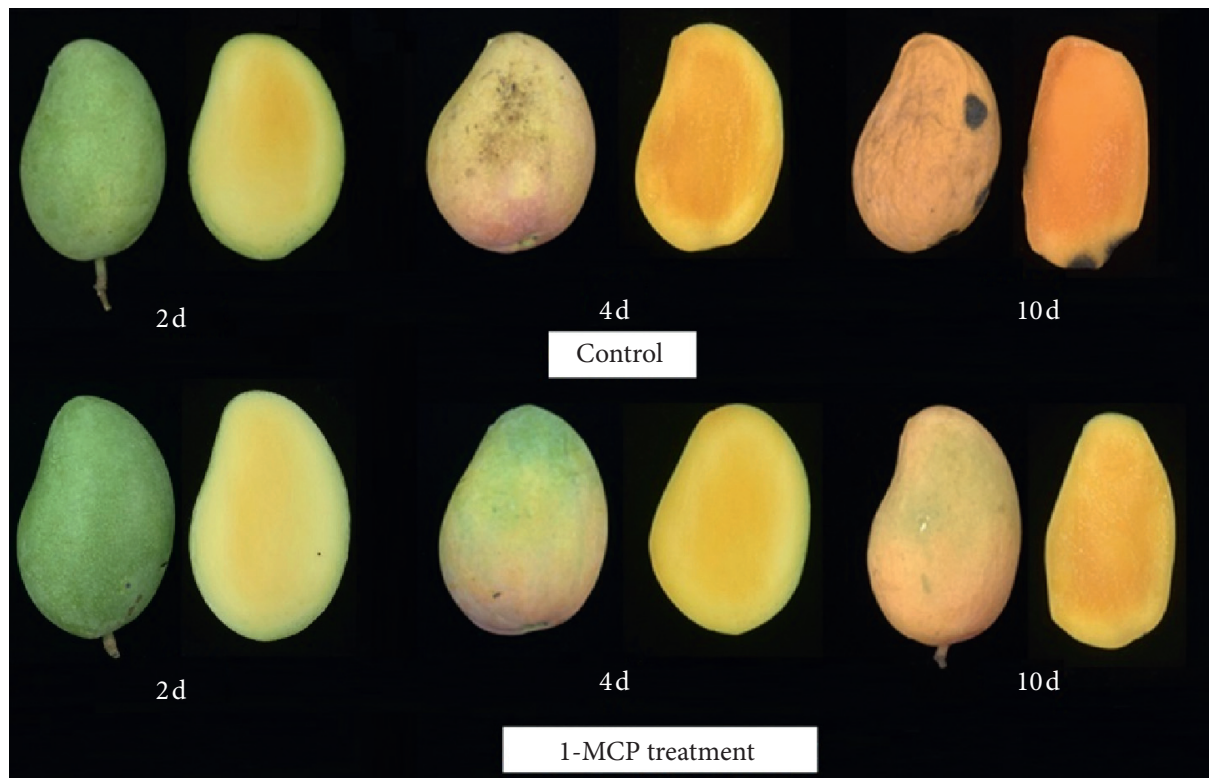

(a)
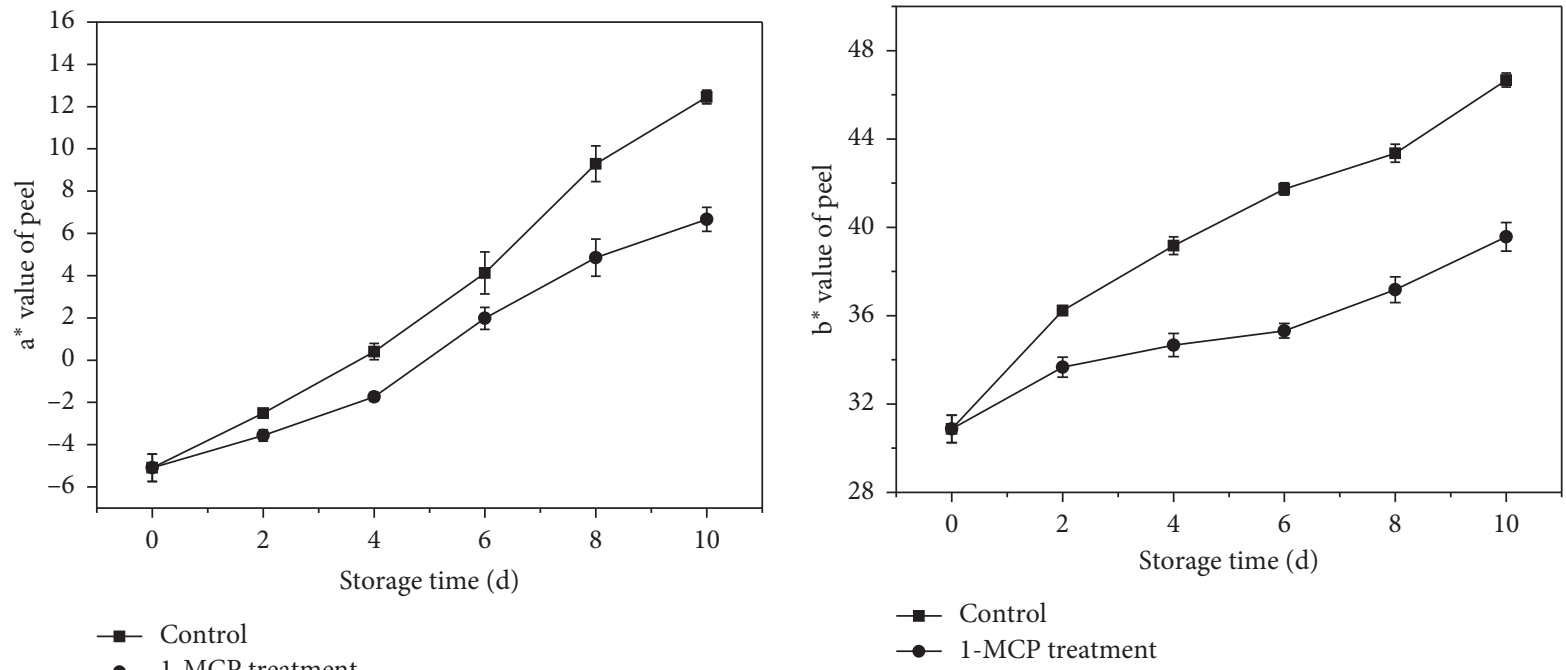

(b)

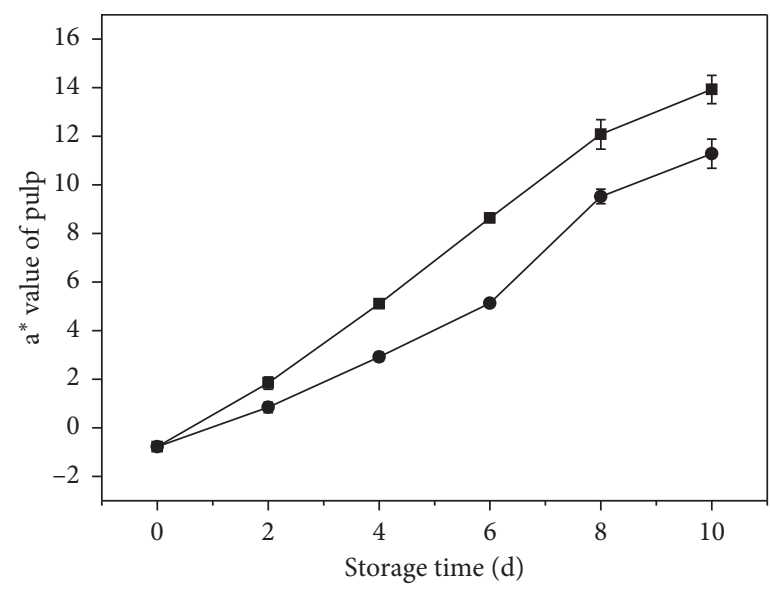

(c)

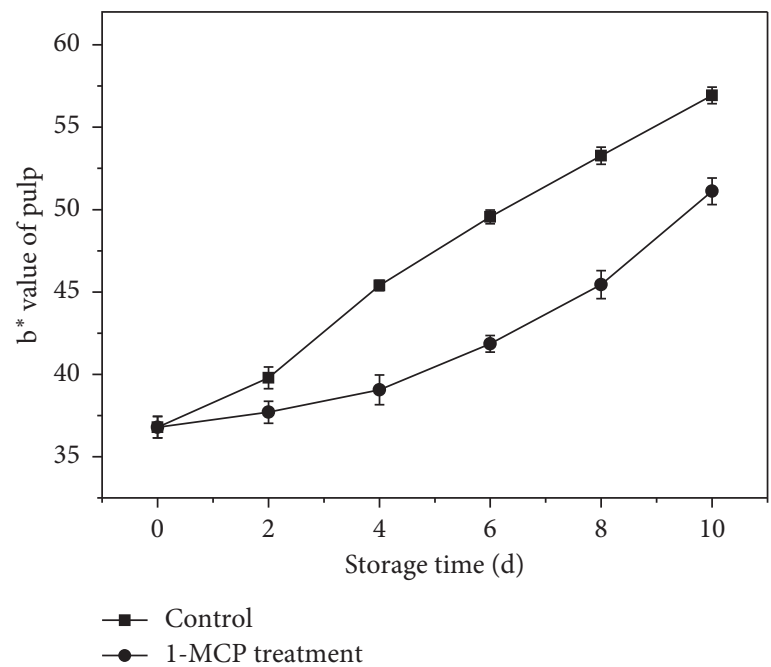

(d)

(e)

Figure 2: Effects of 1-MCP treatment on colour (a), $a^{*}$ value (b) and $b^{*}$ value (c) of peel, and $a^{*}$ value (d) and $b^{*}$ value (e) of pulp of mango during storage at $25^{\circ} \mathrm{C}$. The data are the means of triplicates \pm standard deviations. 
days. All results demonstrated that 1-MCP treatment had a good effect on the maintenance of colour of mango fruit stored at ambient temperature.

\subsection{Effects of 1-MCP on Respiration and Ethylene Generation.} Increased respiration rates could be associated with fruit aging and disease progress over the period of storage. The respiration rate of mango fruit displayed a representative climacteric mode over the period of storage (Figure 3(a)). Respiration rates demonstrated the increasing trends over the storage of all fruits. It was also found that fruit treated with 1-MCP demonstrated a lower respiration rate than that of the control group. Ethylene is naturally produced in postharvest mango and quickly leads to overripening. Fruit treated with 1-MCP displayed both retarded and inhibited ethylene generation over the whole storage period, compared with untreated fruit (Figure 3(b)). The control fruit displayed climacteric peaks of ethylene generation on day 4 at $25^{\circ} \mathrm{C}$, and production of ethylene in the 1-MCP-treated group peaked on day 6 of storage, 2 days later compared with the control group. These results indicated that 1-MCP treatment abolished the onset of respiratory climacteric and suppressed $\mathrm{CO}_{2}$ production during storage.

3.4. Effects of 1-MCP on Oxidative Stress. During fruit aging, the excessive production of reactive oxygen species (ROS) was caused by membrane lipids due to peroxidation and the formation of poisonous products including MDA, which was a secondary final product of polyunsaturated fatty acid oxidation [26]. As a demonstrator of the development of fruit decay, MDA usually symbolized the content of lipid peroxides and the structural wholeness of cell membranes [27]. As demonstrated in Figure 4, in both groups, MDA was increased throughout the entire storage duration. In contrast with the control group, 1-MCP treatment alleviated the uptrend of MDA level in mango fruit, and 1-MCP delayed MDA increase significantly $(P<0.05)$ after day 2 during storage.

POD activity is related to plant aging and pressure by membrane alteration and lipid degradation related to senescence. As can be seen from Figure 5(a), POD activity increased initially and then decreased after day 8. POD activity in fruit treated with 1-MCP was initially dramatically higher $(P<0.05)$ when compared to the control group, but there were no statistically significant differences after day 6 . CAT activity demonstrated a peak on day 6 , followed by a decrease (Figure 5(b)). Fruit treated with 1-MCP and control had similar CAT activity during the 2-day storage period. Nevertheless, CAT activity in fruit treated with 1-MCP was significantly higher $(P<0.05)$ than that in control fruit on days 4,6 , and 8 . CAT activity in all fruits treated with 1-MCP was also dramatically more elevated than that in the control group. As can be seen from Figure 5(c), SOD activity in fruit treated with $1-\mathrm{MCP}$ was significantly higher $(P<0.05)$ than that in control on days 2,4 , and 6 . The above results indicated that 1-MCP effectively inhibited MDA content increase and enhanced antioxidant enzyme activities so as to reduce oxidative damage and alleviate oxidative stress of mango fruit during storage.

3.5. Effects of 1-MCP on Fruit Softening. As can be seen from Figure 6(a), PE activity showed an increasing trend during storage of all mango fruits. Fruits showed significant difference in PE activity between treatments, and lower values were presented by $1-\mathrm{MCP}$ treatment for all storage periods. Mango fruit stored at $25^{\circ} \mathrm{C}$ showed a typical climacteric peak in EGase activity, and the fruit displayed a significantly stable rise in EGase enzyme activity, whereas the activity declined greatly from day 8 to day 10 (Figure 6(b)). 1-MCP played an effective role in the delay of EGase activity during the entire storage period, and EGase activity of 1-MCP treatment fruits was lower and differed significantly from control treatment. Rapid softening was associated with PG activity which degrades the pectin in the cell wall matrix, causing a decrease in cell wall content and leading to softening. From Figures 6(c) and $6(\mathrm{~d})$, exo-PG and endo-PG activity in all fruits showed a linear increase. Compared to the control, treatment with 1MCP dramatically reduced exo-PG activity in mango fruit stored at $25^{\circ} \mathrm{C}$ (Figure 6(c)). As can be seen from Figure 6(d), fruit treated with 1-MCP did not exhibit dramatic changes in endo-PG activity during the first 2 days. However, fruit treated with 1-MCP displayed lower endo-PG activity after day 2 than that of untreated fruit.

\section{Discussion}

1-MCP, extensively applied in postharvest storage, has been proved to play an extremely effective role in the maintenance of fruit quality $[28,29]$. Previous studies demonstrated the advantages of 1-MCP treatment in the control of postharvest pathogens. According to previous reports, 1-MCP treatment reduced ethylene generation, respiration, and chlorophyll degradation, in addition to retarding softening and reducing colour variation [30].

1-MCP treatment can maintain excellent quality in many fruits. Some reports have indicated that 1-MCP treatment could maintain excellent quality and increase storage time in plum [31], apple [32], pear [13], and peach fruit [33]. In the present study, 1-MCP treatment of mango fruit helped to maintain greater firmness and weight than in control fruit during storage (Figure 1). Reduced enzyme activity may be the reason for the reduction in fruit softening due to 1-MCP treatment, for fruit firmness is significantly and negatively correlated with activities of diverse softening enzymes, including PE, EGase, exo-PG, and endo-PG [18]. PE removes methoxyl groups from highly or partially esterified galacturonan and is supposed to play a key part in cell wall metabolism [34]. Fruit treated with 1-MCP exhibited dramatically higher PE activity at both ambient and low temperatures than did control fruit (Figure 6(a)); as a result, 1MCP treatment delayed the increase of PE activity, and Razzaq et al. obtained similar findings [35]. As a cell wall degrading enzyme, EGase plays a significant part in the softening of mango fruit [36]. It has been reported that EGase activity increased over the period of maturity in 


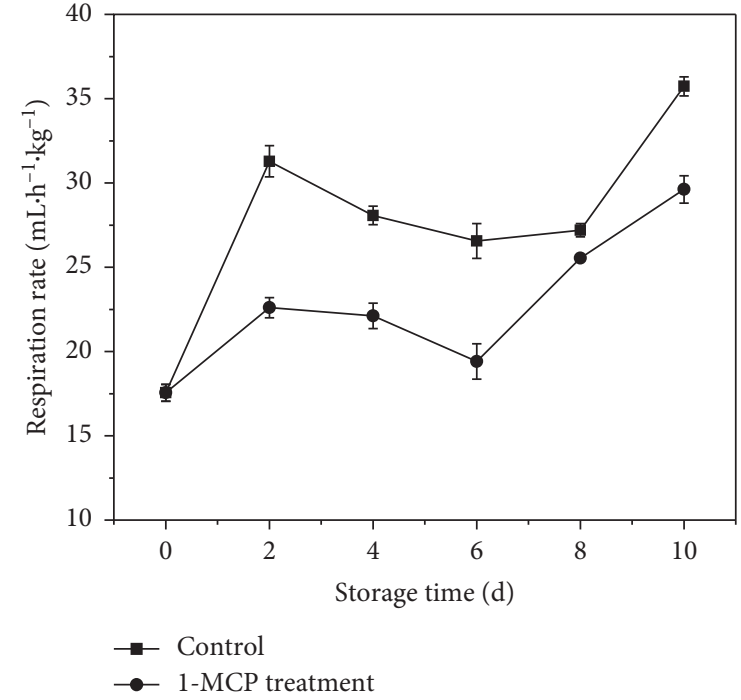

(a)

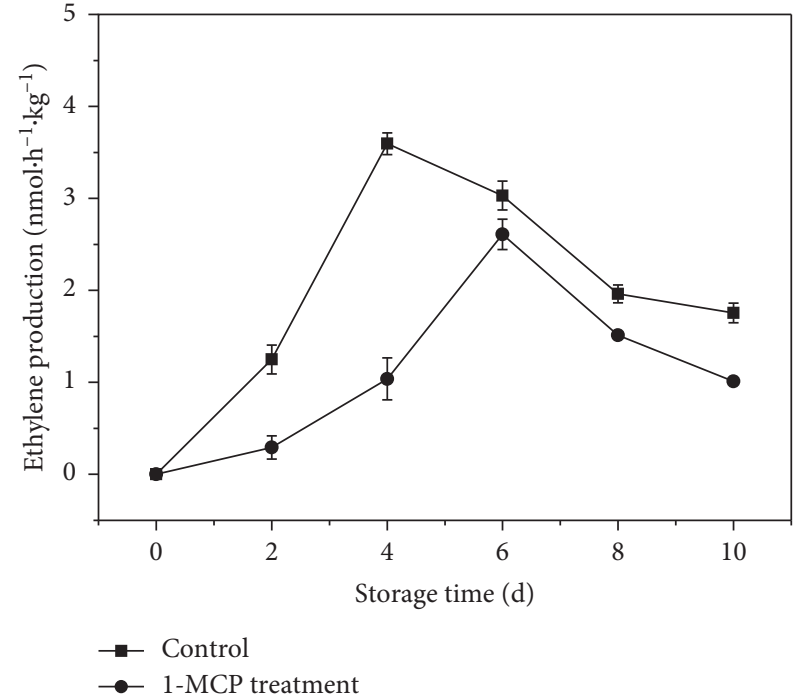

(b)

FIGURE 3: Effects of 1-MCP treatment on respiration rate (a) and ethylene production (b) of mango fruit during storage at $25^{\circ} \mathrm{C}$. The data are the means of triplicates \pm standard deviations.

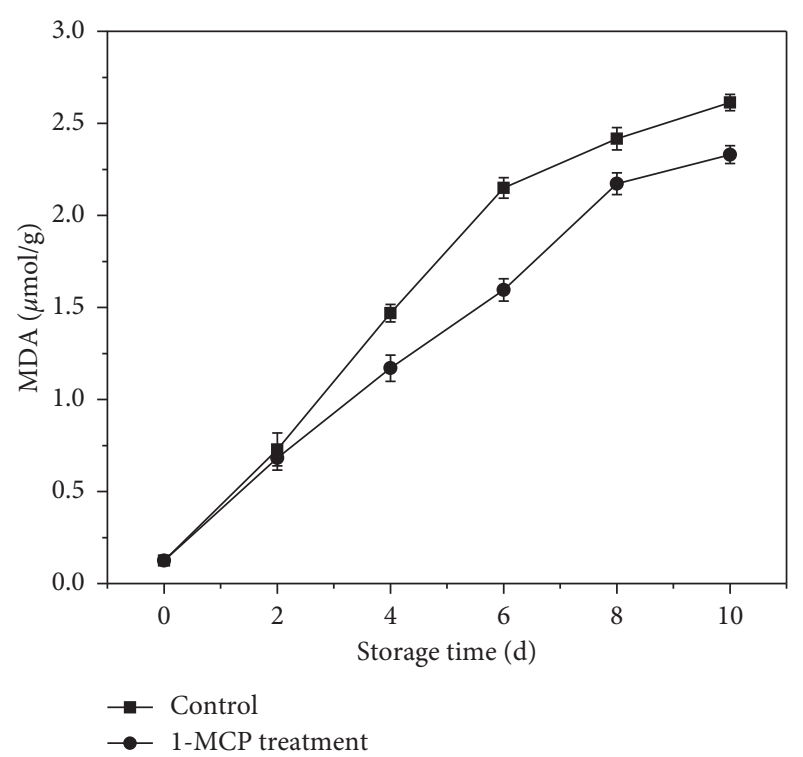

Figure 4: Effects of 1-MCP treatment on MDA of mango fruit during storage at $25^{\circ} \mathrm{C}$. The data are the means of triplicates \pm standard deviations.

"Samar Bahisht Chaunsa" mango [17]. In the present research, fruit treated with 1-MCP showed complete suppression of EGase enzyme activity compared to the control (Figure 6(b)). Banana fruit showed a similar trend in EGase activity because of the gradual increase of enzyme activity up to the fourth day, followed by a significant decrease until the seventh day [37]. The present study revealed an increase of exo- and endo-PG activities over the period of maturity (Figures 6(c) and 6(d)), which was accelerated by ethylene treatment and inhibited by 1-MCP treatment and was linked with decreased loss of firmness. Similar impacts of 1-MCP in delaying fruit softening have been seen in various fruits, including tomato, avocado, kiwifruit, peach, plum, and apple $[18,31]$.

Previous studies have shown that 1-MCP treatment was conducive to the maintenance of mango fruit quality over postharvest storage. In this research, 1-MCP treatment maintained excellent quality in mango fruit (Figures 1 and 2). Treated with 1-MCP maintained higher TSS levels (Figure 1(b)). The decrease of TSS in 1-MCP-treated fruit may be due to decline of the amount of carbohydrates and pectins, partial hydrolysis of protein, and decomposition of glycosides into subunits during respiration. In addition, TA reduction was delayed in fruit treated with 1-MCP compared to control fruit (Figure 1(c)). 1-MCP treatment delayed the colour change of both mango fruit peel and pulp (Figure 2), demonstrating that 1-MCP treatment had a good effect on the maintenance of colour of mango fruit stored at ambient temperature. Ethylene is known to play a key role in the maturity and aging of fruit due to its effect on the expression of genes associated with ripening. 1-MCP has reduced ethylene generation in strawberry, apricot, and plum and suppressed ethylene generation in apple [28]. In this study, postharvest 1-MCP treatment inhibited the climacteric peaks of both ethylene generation and respiration rate in mango fruit over the period of ripening (Figure 3), confirming the findings of previous surveys with other plants. Inhibition of ethylene by 1-MCP is based on the ability of 1MCP to irreversibly bind to ethylene receptors, consequently diminishing the normal increase in ACS and ACO enzyme activities during ripening and senescence [38, 39].

Antioxidant enzymes, associated with both senescence and defense responses play a significant role in suppressing oxidative stress. POD, CAT, and SOD are vital enzymes that can protect cells from oxidative damage by scavenging ROS [22]. Accumulation of ROS causes oxidative injury and 


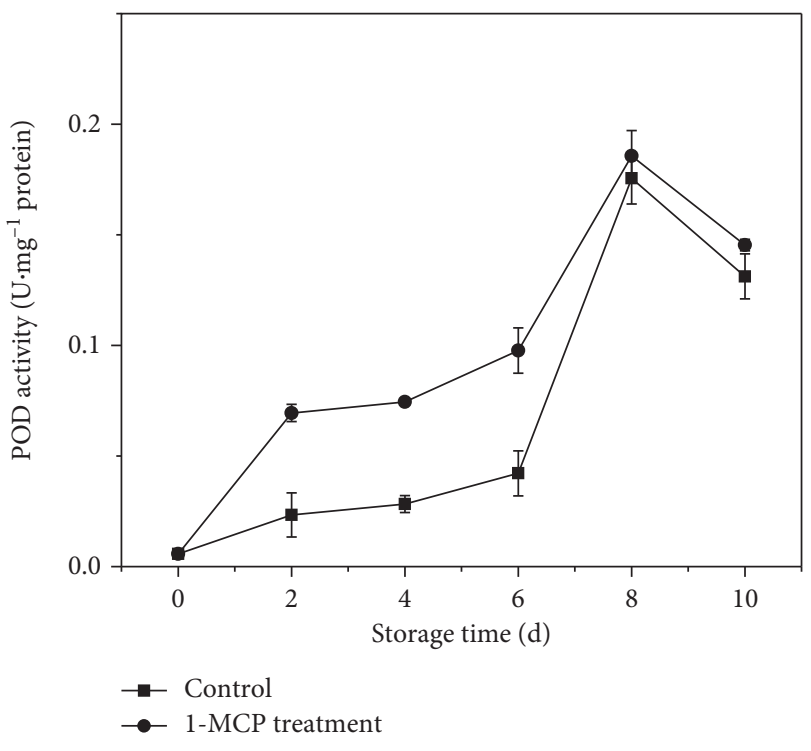

(a)

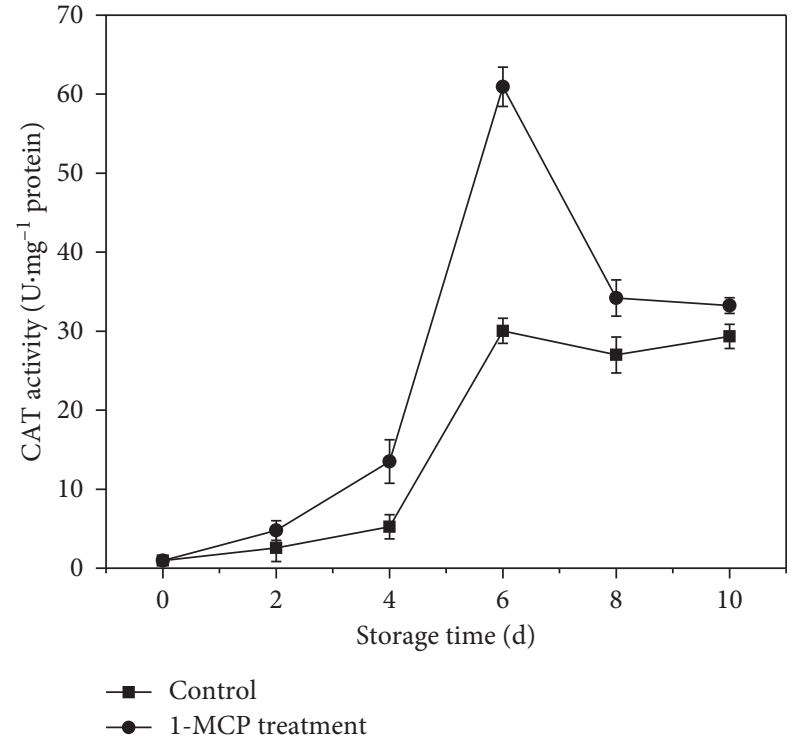

(b)

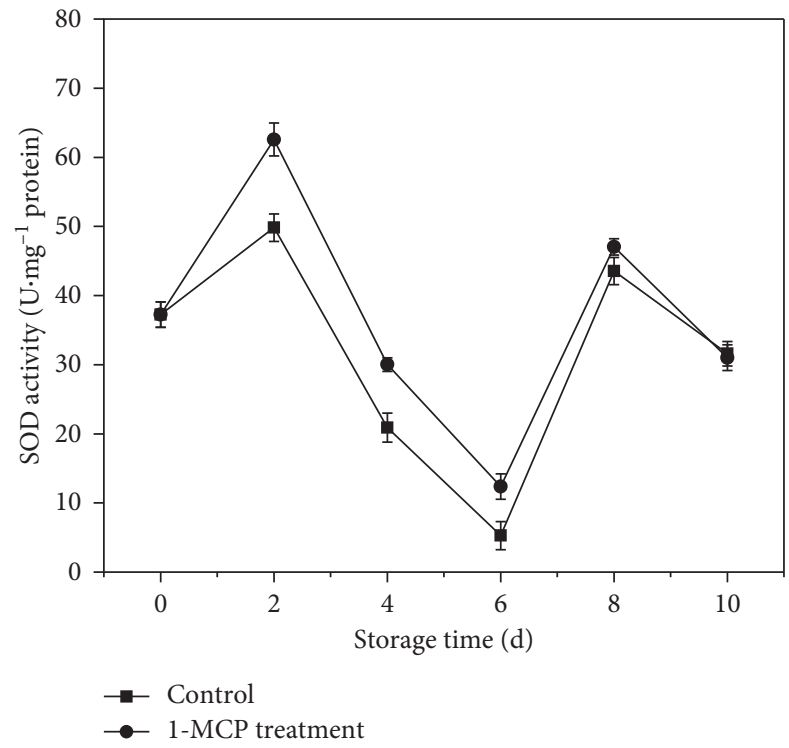

(c)

Figure 5: Effects of 1-MCP treatment on POD activity (a), CAT activity (b), and SOD activity (c) of mango fruit during storage at $25^{\circ} \mathrm{C}$. The data are the means of triplicates \pm standard deviations.

accelerates the development of senescence and various senescence-related disorders. With the increase of ROS, chain reactions start in which SOD catalyzes the dismutation of the superoxide radical to molecular $\mathrm{O}_{2}$ and $\mathrm{H}_{2} \mathrm{O}_{2}$, and $\mathrm{H}_{2} \mathrm{O}_{2}$ is then detoxified by CAT and POD [40]. CAT reduces $\mathrm{H}_{2} \mathrm{O}_{2}$ into $\mathrm{H}_{2} \mathrm{O}$ and $\mathrm{O}_{2}$, whereas POD decomposes $\mathrm{H}_{2} \mathrm{O}_{2}$ by oxidation of cosubstrates such as phenolic compounds. In this study, the MDA content of fruit treated with 1-MCP was lower than that in the control fruit after day 2 (Figure 4), indicating that 1-MCP treatment might somehow be responsible for controlling the excessive production of ROS and suppress lipid peroxidation over the period of storage of mango fruit. Meanwhile, 1-MCP treatment helped to maintain dramatically high CAT, POD, and SOD activities during storage (Figure 5). These antioxidative enzymes could eliminate ROS, which was excessively produced in fruit, delay the peroxidation of membrane lipids, and relieve oxidative stress in postharvest fruit, thereby controlling the ripening and aging over the period of storage to some degree [41]. Consequently, 1-MCP treatment suppressed oxidative stress and the excessive production of ROS principally through maintaining the high activity of antioxidative enzymes to limit decay in mango fruit.

In conclusion, treatment with 1-MCP dramatically retarded softening and slowed both senescence and corruption of mango fruit through protecting membrane structures from peroxidation. Additionally, ethylene production was inhibited and the respiration rate reduced in fruit treated 


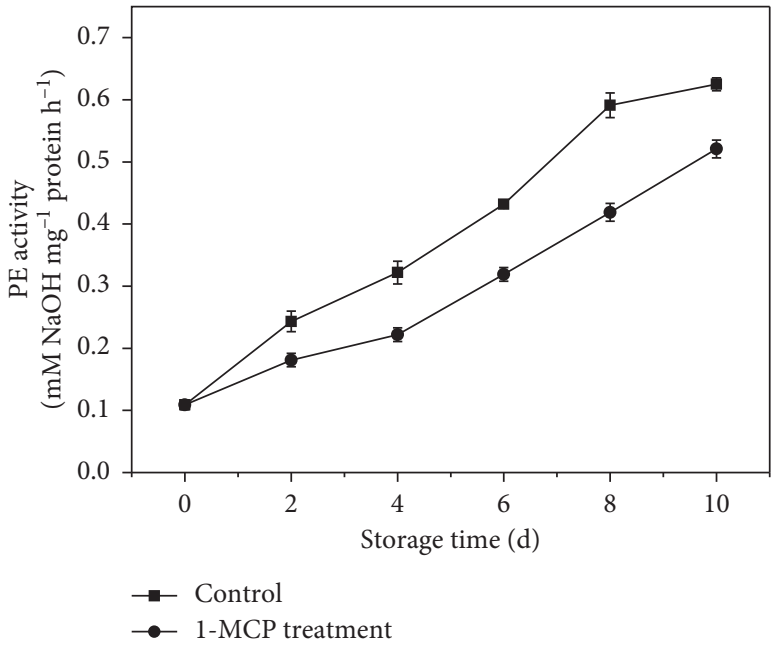

(a)

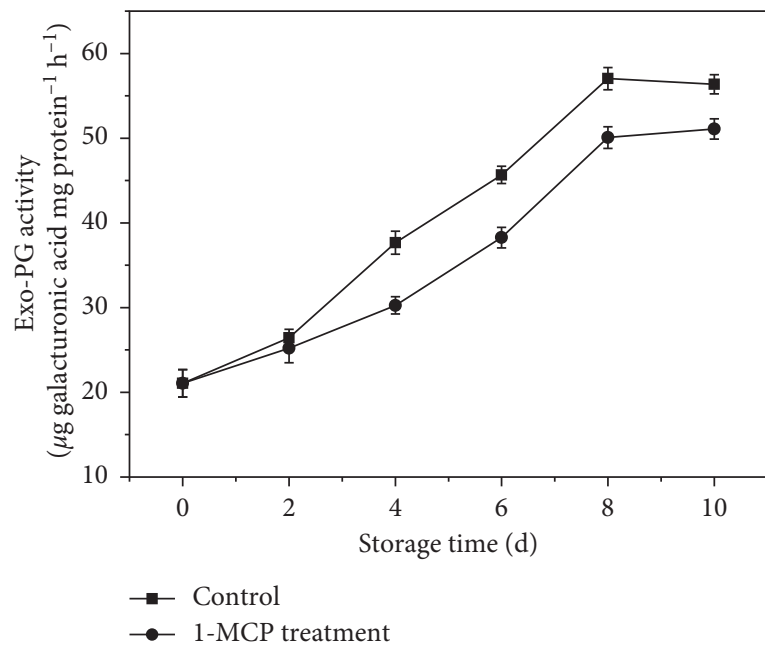

(c)

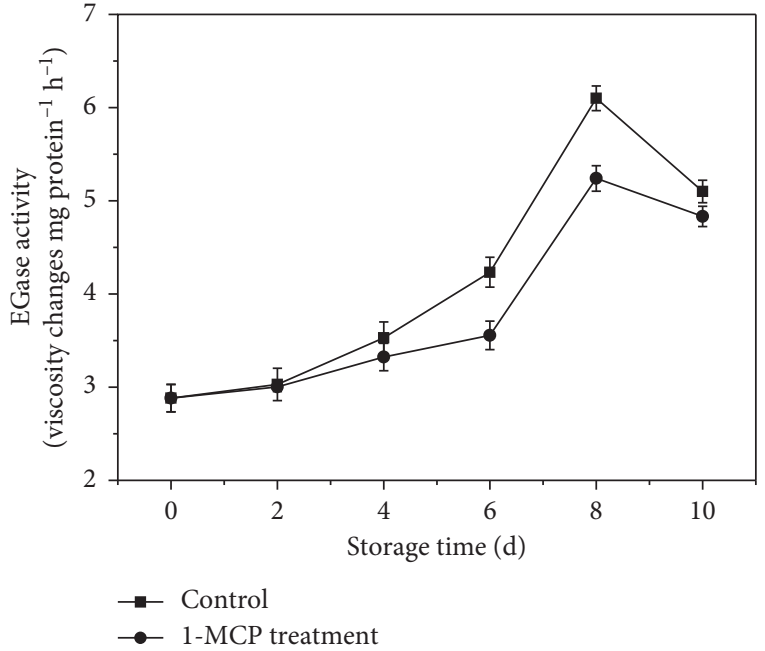

(b)

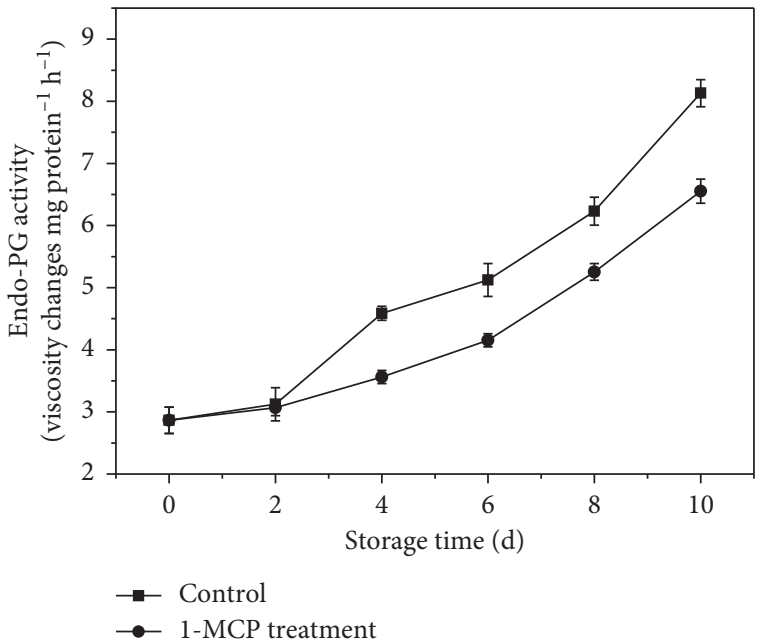

(d)

FIGURe 6: Effects of 1-MCP treatment on PE activity (a), EGase activity (b), exo-PG activity (c), and endo-PG activity (d) of mango fruit during storage at $25^{\circ} \mathrm{C}$. The data are the means of triplicates \pm standard deviations.

with 1-MCP. 1-MCP treatment showed complete suppression of the activities of softening enzymes: PE, EGase, exo$\mathrm{PG}$, and endo-PG. These results indicated that 1-MCP treatment represented an excellent alternative for maintaining its appearance and nutritional values during storage. Fruit treated with 1-MCP also demonstrated differential activities of fruit softening and antioxidant enzymes during storage, warranting more research studies on the impacts of 1-MCP on the gene expression associated with these enzymes. Whether 1-MCP can modify ripening and agingrelated genes needs to be verified in further research.

\section{Data Availability}

All data included in this study are available upon request by contact with the corresponding author.

\section{Conflicts of Interest}

The authors declare that they have no conflicts of interest.

\section{Authors' Contributions}

Li Li and Changbao Li contributed equally to this study.

\section{Acknowledgments}

This research was supported by the National Key R\&D Program of China (Grant no. 2018YFD0401300), National Natural Science Foundation of China (Grant nos. 31560467, 31660589, 31560006, and 31860579), Special Fund for Guangxi Bagui Scholars (Grant no. [2016]21), Central Guides Local Science and Technology Development Project (Grant no. Gui Ke ZY1949014), Science and Technology Major Project of Guangxi (Grant nos. Gui Ke AA17204038 and AA17204042), Guangxi Scientific Research and Technological Development Projects (Grant no. Gui Ke AD19110141), Postdoctoral Foundation of Guangxi Academy of Agricultural Sciences (Grant no. 2018029), Guangxi Natural Science Foundation (Grant no. 2018GXNSFAA281149), and Foundation of Fundamental 
Research Project from Guangxi Academy of Agricultural Sciences (Grant nos. JZ202019, 2019Z10, 2018YT27, 2018YM04, 2017JZ10, 2016JZ11, and 2015YT86).

\section{References}

[1] K. Hu, A. G. Dars, Q. Liu, B. Xie, and Z. Sun, "Phytochemical profiling of the ripening of Chinese mango (Mangifera indica L.) cultivars by real-time monitoring using UPLC-ESI-QTOFMS and its potential benefits as prebiotic ingredients," Food Chemistry, vol. 256, no. 8, pp. 171-180, 2018.

[2] K. Prasad and R. R. Sharma, "Salicylic acid influences lenticel discolouration and physiological and biochemical attributes of mango (Mangifera indica L.) fruits," Journal of Plant Biochemistry and Biotechnology, vol. 27, no. 3, pp. 293-299, 2018.

[3] S. U. Samart, B. Soottawat, K. Supaluck, and R. Saroat, "Optimization of antioxidants and tyrosinase inhibitory activity in mango peels using response surface methodology," LWT-Food Science and Technology, vol. 64, no. 2, pp. 742749, 2015.

[4] Z. Li, N. Wang, G. S. Vijaya Raghavan, and C. Vigneault, "Ripeness and rot evaluation of "Tommy Atkins" mango fruit through volatiles detection," Journal of Food Engineering, vol. 91, no. 2, pp. 319-324, 2009.

[5] E. Pesis, D. Aharoni, Z. Aharon, R. Ben-Arie, N. Aharoni, and Y. Fuchs, "Modified atmosphere and modified humidity packaging alleviates chilling injury symptoms in mango fruit," Postharvest Biology and Technology, vol. 19, no. 1, pp. 93-101, 2000.

[6] J. Faasema, J. S. Alakali, and J. O. Abu, "Effects of storage temperature on 1-methylcyclopropene-treated mango (Mangnifera indica) fruit varieties," Journal of Food Processing and Preservation, vol. 38, no. 1, pp. 289-295, 2012.

[7] H. M. Yashoda, T. N. Prabha, and R. N. Tharanathan, "Mango ripening: changes in cell wall constituents in relation to textural softening," Journal of the Science of Food and Agriculture, vol. 86, no. 1, pp. 713-721, 2006.

[8] E.-H. Chang, J.-S. Lee, and J.-G. Kim, "Cell wall degrading enzymes activity is altered by high carbon dioxide treatment in postharvest "Mihong" peach fruit," Scientia Horticulturae, vol. 225, no. 18, pp. 399-407, 2017.

[9] A. S. Khan and Z. Singh, "1-MCP application suppresses ethylene biosynthesis and retards fruit softening during cold storage of "Tegan Blue" Japanese plum," Plant Science, vol. 176, no. 4, pp. 539-544, 2009.

[10] G. E. Schaller and B. M. Binder, "Inhibitors of ethylene biosynthesis and signaling," Methods in Molecular Biology, vol. 1573, no. 4, pp. 223-235, 2017.

[11] Q. Wang, T. Lai, G. Qin, and S. Tian, "Response of jujube fruits to exogenous oxalic acid treatment based on proteomic analysis," Plant and Cell Physiology, vol. 50, no. 2, pp. 230242, 2009.

[12] Y.-S. Wang, S.-P. Tian, and Y. Xu, "Effects of high oxygen concentration on pro- and anti-oxidant enzymes in peach fruits during postharvest periods," Food Chemistry, vol. 91, no. 1, pp. 99-104, 2005.

[13] D. Yu, W. Yan, and T. C. Einhorn, "Postharvest physiology, storage quality and physiological disorders of "Gem" pear (Pyrus communis L.) treated with 1-methylcyclopropene," Scientia Horticulturae, vol. 240, no. 20, pp. 631-637, 2018.

[14] Q. Yang, L. Wang, F. Li, J. Ma, and Z. Zhang, "Impact of 1MCP on postharvest quality of sweet cherry during cold storage," Frontiers of Agriculture in China, vol. 5, no. 4, pp. 631-636, 2012.

[15] W. F. Li, J. Mao, X. W. Li et al., "Effects of cepa and 1-mcp on flower bud differentiation of apple cv. "nagafu no. 2" grafted on different rootstocks," Journal of Plant Growth Regulation, vol. 71, no. 12, pp. 1-13, 2018.

[16] Z. Q. Zhang, S. P. Tian, Z. Zhu, Y. Xu, and G. Z. Qin, "Effects of 1-methylcyclopropene (1-MCP) on ripening and resistance of jujube (Zizyphus jujuba cv. Huping) fruit against postharvest disease," LWT-Food Science and Technology, vol. 71, no. 12, pp. 13-19, 2012.

[17] K. Razzaq, Z. Singh, A. S. Khan, S. A. K. U. Khan, and S. Ullah, "Role of 1-MCP in regulating "Kensington Pride" mango fruit softening and ripening," Plant Growth Regulation, vol. 78, no. 3, pp. 401-411, 2016.

[18] B. Wang, J. Wang, X. Feng, L. Lin, Y. Zhao, and W. Jiang, "Effects of 1-MCP and exogenous ethylene on fruit ripening and antioxidants in stored mango," Plant Growth Regulation, vol. 57, no. 2, pp. 185-192, 2009.

[19] L. Li, J. Li, J. Sun et al., "Effects of 2-butanol on quality and physiological characteristics of longan fruit stored at ambient temperature," Postharvest Biology and Technology, vol. 101, pp. 96-102, 2015.

[20] AOAC, Official Methods of Analysis, Association of Official Analytical Chemist, Washington, DC, USA, 2000.

[21] B. B. Mishra, S. Gautam, and A. Sharma, "Browning of freshcut eggplant: impact of cutting and storage," Postharvest Biology and Technology, vol. 67, pp. 44-51, 2012.

[22] J. Sun, X. You, L. Li et al., "Effects of a phospholipase D inhibitor on postharvest enzymatic browning and oxidative stress of litchi fruit," Postharvest Biology and Technology, vol. 62, no. 3, pp. 288-294, 2011.

[23] A. R. Vicente, G. A. Martínez, A. R. Chaves, and P. M. Civello, "Effect of heat treatment on strawberry fruit damage and oxidative metabolism during storage," Postharvest Biology and Technology, vol. 40, no. 2, pp. 116-122, 2006.

[24] D. Liu, J. Zou, Q. Meng, and W. Jiang, "Uptake and accumulation and oxidative stress in garlic (Allium sativm L.) under lead phytotoxicity," Ecotoxicology, vol. 18, no. 2, pp. 134-143, 2009.

[25] H.-W. Zhou, S. Lurie, A. Lers, A. Khatchitski, L. Sonego, and R. Ben Arie, "Delayed storage and controlled atmosphere storage of nectarines: two strategies to prevent woolliness," Postharvest Biology and Technology, vol. 18, no. 2, pp. 133-141, 2000.

[26] J. Liu, M. Wisniewski, S. Droby et al., "Increase in antioxidant gene transcripts, stress tolerance and biocontrol efficacy of Candida oleophila following sublethal oxidative stress exposure," FEMS Microbiology Ecology, vol. 80, no. 3, pp. 578-590, 2012.

[27] F. M. Yang, H. M. Li, F. Li et al., "Effect of nano-packing on preservation quality of fresh strawberry (Fragaria ananassa Duch. cv Fengxiang) during storage at $4^{\circ} \mathrm{C}$," Journal of Food Science, vol. 75, no. 3, pp. C236-C240, 2010.

[28] S. M. Blankenship and J. M. Dole, "1-Methylcyclopropene: a review," Postharvest Biology and Technology, vol. 28, no. 1, pp. 1-25, 2003.

[29] D. J. Huber, "Suppression of ethylene responses through application of 1-methylcyclopropene: a powerful tool for elucidating ripening and senescence mechanisms in climacteric and nonclimacteric fruits and vegetables," HortScience, vol. 43, no. 1, pp. 106-111, 2008.

[30] B. Sun, H. Yan, N. Liu, J. Wei, and Q. Wang, "Effect of 1-MCP treatment on postharvest quality characters, antioxidants and 
glucosinolates of Chinese kale," Food Chemistry, vol. 131, no. 2, pp. 519-526, 2012.

[31] A. S. Khan and Z. Singh, "1-MCP regulates ethylene biosynthesis and fruit softening during ripening of "Tegan Blue" plum," Postharvest Biology and Technology, vol. 131, no. 2, pp. 298-306, 2007.

[32] X. Yang, J. Song, L. Du et al., "Ethylene and 1-MCP regulate major volatile biosynthetic pathways in apple fruit," Food Chemistry, vol. 194, pp. 325-336, 2016.

[33] A. Ortiz, J. Graell, M. L. López, G. Echeverría, and I. Lara, "Volatile ester-synthesising capacity in "Tardibelle" peach fruit in response to controlled atmosphere and 1-MCP treatment," Food Chemistry, vol. 123, no. 3, pp. 698-704, 2010.

[34] T. D. Phan, W. Bo, G. West, G. W. lycett, and G. A. Tucker, "Silencing of the major salt-dependent isoform of pectinesterase in tomato alters fruit softening," Plant Physiology, vol. 144, no. 4, pp. 1960-1967, 2007.

[35] K. Razzaq, A. S. Khan, A. U. Malik, and M. Shahid, "Ripening period influences fruit softening and antioxidative system of "Samar Bahisht Chaunsa" mango," Scientia Horticulturae, vol. 160, no. 27, pp. 108-114, 2013.

[36] A. Chourasia, V. A. Sane, R. K. Singh, and P. Nath, "Isolation and characterization of the MiCell gene from mango: ripening related expression and enhanced endoglucanase activity during softening," Plant Growth Regulation, vol. 56, no. 2, pp. 117-127, 2008.

[37] S. Lohani, P. K. Trivedi, and P. Nath, "Changes in activities of cell wall hydrolases during ethylene-induced ripening in banana: effect of 1-MCP, ABA and IAA," Postharvest Biology and Technology, vol. 31, no. 2, pp. 119-126, 2004.

[38] E. C. Sisler and M. Serek, "Inhibitors of ethylene responses in plants at the receptor level: recent developments," Physiologia Plantarum, vol. 100, no. 3, pp. 577-582, 1997.

[39] H. J. D. Lalel, Z. Singh, and S. C. Tan, "The role of ethylene in mango fruit aromavolatiles biosynthesis," Journal of Pomology \& Horticultural Science, vol. 78, no. 4, pp. 85-496, 2003.

[40] G. Noctor and C. H. Foyer, "Ascorbate and glutathione: keeping active oxygen under control," Annual Review of Plant Physiology and Plant Molecular Biology, vol. 49, no. 1, pp. 249-279, 1998.

[41] S. S. Gill and N. Tuteja, "Reactive oxygen species and antioxidant machinery in abiotic stress tolerance in crop plants," Plant Physiology and Biochemistry, vol. 48, no. 12, pp. 909930, 2010. 